\title{
Construcción de identidades masculinas en el género policial y criminal latinoamericano
}

\author{
Román Setton \\ Universidad de Buenos Aires, Instituto de Filología y Literaturas \\ Hispánicas “Dr. Amado Alonso”, Consejo Nacional de Investigaciones \\ Científicas y Técnicas, Argentina \\ romansetton@gmail.com
}

\author{
Gerardo Pignatiello \\ Binghamton University \\ gpignati@binghamton.edu
}

Believe me, past a certain age, a man without a family can be a bad thing (Marty, True Detective)

Los estudios del policial desde una perspectiva de género (gender) han sido fundamentales para comprender una dimensión muchas veces soslayada: la importancia de los aspectos relacionados con la sexualidad, la identidad y la expresión de género en las principales figuras de estas ficciones: detective, víctima y asesino. En los últimos años, se han multiplicado los estudios que analizan los personajes femeninos, homosexuales y queers, así como las tramas armadas alrededor de diversos modos de violencia y crimen patriarcales. Un aspecto de este gran complejo temático apenas ha sido explorado: la conformación de las diversas formas de masculinidad. Naturalmente, esto no está desvinculado al hecho de que, en la oposición semiótica de masculinidad y femineidad, la masculinidad es el término inadvertido. Sin embargo, es claro que la estructura de desigualdad que instala la división de género no puede sostenerse sin violencia. Como afirma Robert W. Connell, el "género dominante es, abrumadoramente, el que sostiene y usa los medios de violencia. Los hombres están armados muchísimo más a menudo que las mujeres" (1995: 17). Asimismo, el orden patriarcal impone ciertas formas adecuadas o disonantes de afectos y emociones, que con frecuencia funcionan en la trama policial como motores de las acciones de esas masculinidades en disputa y en busca de afirmación y consolidación. De hecho, las instituciones encargadas de sostener el orden -en la realidad y en las ficciones literarias, cinematográficas, televisivas, etcétera- se desarrollaron en gran medida como instituciones homosociales. Desde el comienzo, además, los individuos que logran resolver los misterios que importan la aparición súbita de cadáveres femeninos en las nuevas metrópolis cosmopolitas se encuentran ellos mismos marginados por completo de la sociedad y, ante todo, de los modelos de masculinidad hegemónicos y los correspondientes mandatos vigentes. El detective y su ayudante, outsiders por completo en la nueva sociedad, incapaces de 
tener un trabajo regular y productivo o conformar una familia tradicional encuentran su pequeño lugar al colaborar con la resolución de los misterios sociales y la restitución del orden. Sólo en estas condiciones, su bizarrerie y su distanciamiento de los modelos patriarcales son tolerados apenas en la nueva sociedad, surgida como consecuencia de la "reorganización del trabajo doméstico, la vida familiar, la crianza de los hijos, la sexualidad, las relaciones entre hombres y mujeres y la relación entre producción y reproducción en la Europa de los siglos XVI y XVII." (Federici, 2010: 18) Esto aparece con toda claridad en el relato considerado casi universalmente el primero del género, "Los crímenes de la calle Morgue".

Mientras estaba en París durante la primavera y parte del verano de $18 . .$. , conocí a Monsieur C. Auguste Dupin. Pertenecía este joven caballero a una excelente, mejor dicho, ilustre familia, pero una serie de adversos sucesos lo habían reducido a tal pobreza que sucumbió la energía de su carácter y renunció a sus ambiciones mundanas y a ocuparse de restablecer su fortuna. Gracias a la cortesía de sus acreedores, le quedó una pequeña parte de su patrimonio, y con la renta que ésta producía, gracias a una economía rigurosa, encontró el medio de afrontar las necesidades de su vida, sin preocuparse en absoluto por lo más superfluo. Su único lujo eran los libros, y en París estos son fáciles de adquirir.

Nuestro conocimiento tuvo lugar en una oscura biblioteca de la rue Montmartre, donde nos puso en estrecha intimidad la coincidencia de buscar los dos un libro muy raro y al mismo tiempo notable. Nos vimos con frecuencia. Yo me había interesado vivamente por la sencilla historia de su familia, que me contó detalladamente con toda la ingenuidad con que un francés se explaya en sus confidencias cuando habla de sí mismo. Por otra parte, me admiraba el número de sus lecturas y, sobre todo, me llegaba al alma el vehemente afán y la viva frescura de su imaginación. La índole de las investigaciones que me ocupaban entonces en París me hizo comprender que la amistad de un hombre semejante era para mí un inapreciable tesoro. Con esta idea, me confié francamente a él. Por último, convinimos en que viviríamos juntos todo el tiempo que durase mi permanencia en la ciudad, y como mis asuntos económicos se desenvolvían menos embarazosamente que los suyos, me fue permitido participar en los gastos de alquiler, y amueblar, de acuerdo con el carácter algo fantástico y melancólico de nuestro común temperamento, una vieja y grotesca casa abandonada hacía ya mucho tiempo, en virtud de ciertas supersticiones que no quisimos averiguar. La casa se estremecía como si fuera a hundirse en un retirado y desolado rincón del Faubourg Saint-Germain.

Si hubiera sido conocida la rutina de nuestra vida en aquel lugar, la gente nos hubiera tomado por locos, aunque quizá de especie inofensiva. Nuestra reclusión era completa. No recibíamos visitas. El lugar de nuestro retiro era celosamente guardado como un secreto para mis antiguos camaradas, y Dupin ya hacía mucho tiempo que había dejado de frecuentar gente o hacerse visible en París. Vivíamos sólo para nosotros.

Una rareza del carácter de mi amigo - ¿cómo calificarla de otro modo?- consistía en estar enamorado de la noche. Pero con esta bizarrerie, como con las otras suyas, condescendía yo tranquilamente, y me entregaba a sus singulares caprichos con un perfecto abandono. No siempre podía estar con nosotros la negra divinidad, pero sí podíamos falsear su presencia. En cuanto la mañana alboreaba, cerrábamos inmediatamente los macizos postigos de nuestra vieja casa y encendíamos un par de bujías intensamente perfumadas y que sólo daban un lívido y débil resplandor, bajo el cual entregábamos nuestras almas a sus ensueños, leíamos, escribíamos o conversábamos, hasta que el reloj nos advertía la llegada de la verdadera oscuridad. Salíamos entonces cogidos del brazo a pasear por las calles, 
continuando la conversación del día y rondando por doquier hasta muy tarde, buscando a través de las estrafalarias luces y sombras de la populosa ciudad esas innumerables excitaciones mentales que no puede procurar la tranquila observación. (Poe, 1979: 569-570)

Se trata, entonces, de hombres venidos a menos, desclasados, casi reducidos a la pobreza, que han renunciado a las actividades mundanas, que llevan una economía extremadamente austera, casi monacal, "sin preocuparse en absoluto por lo más superfluo", atendiendo solamente a la vida intelectual -"su único lujo eran los libros"-, es decir, hombres casi desprovistos por completo de toda corporalidad. Hombres que se conocen al amparo de la noche, unidos por la rareza de los libros, por la extrema peculiaridad de ambos y que de inmediato se vuelven íntimos: "nos puso en estrecha intimidad la coincidencia de buscar los dos un libro muy raro y al mismo tiempo notable". Esto hace que comiencen a verse con frecuencia y de inmediato se muden juntos para mantener un vínculo de amistad, calificada de "inapreciable tesoro", en el cual la admiración es una de las notas fundamentales.

Esos hombres, de carácter "fantástico y melancólico", alejados de todos los vínculos sociales, que viven sólo para ellos mismos, se van a vivir juntos a una especie de casa embrujada, abandonada y aislada. Estos caballeros llevan una vida que, de hacerse pública, concitaría la condena social más allá de su carácter inofensivo. Y, para sumar otra característica que los aleja de la vida común y el intercambio social, aman la noche, la "negra divinidad", que también reproducen de manera artificial dentro del hogar, tapando cualquier ingreso de luz a la casa y encendiendo las bujías necesarias para contar apenas con "un lívido y débil resplandor", hasta que pueden salir de noche "cogidos del brazo a pasear por las calles, continuando la conversación del día y rondando por doquier hasta muy tarde, buscando a través de las estrafalarias luces y sombras de la populosa ciudad [...] innumerables excitaciones mentales". El homoerotismo de estas dos figuras vampirescas es compartido por otro género contemporáneo como el gótico victoriano.

Las mujeres presuntamente asesinadas -en verdad muertas por un simio-, en cambio, son aquellas que no se adaptan al nuevo modelo social, pues viven solas. Ambos géneros, el gótico y el policial, tematizan el espacio moderno: la casa y la calle. Si el gótico crea el nuevo mito de la mujer atrapada que busca escapar del espacio doméstico (the madwoman in the attic ${ }^{1}$ ), el policial no solo trata de los peligros de ese encierro -paradigmáticamente en los misterios de cuarto cerrado, inaugurados por "Los crímenes de la calle Morgue"-, sino también de los de afuera, aquellos que suceden total o parcialmente en el espacio público. Como señala Rita Segato, la reclusión de la mujer en el espacio doméstico aumenta su mortalidad a manos de los hombres (2016: 20). Al mismo tiempo, la ocupación o el disfrute del espacio público por parte de la mujer es tomado como un desafío a la organización social según las divisiones jerárquicas de género, sus mandatos y sus pautas establecidas de manera más o menos explícita. Por lo tanto, es probable que esa "transgresión" sea "castigada". Así, las mujeres quedan expuestas a la violencia salvaje, animal que todavía amenaza a la ciudad, mientras que estos dos hombres, los detectives, que no colaboran con la producción de bienes ni con la reproducción de la especie, encuentran su lugar marginal en la sociedad al explicar los misterios de esta violencia que amenaza con destruir el orden establecido. Como sostiene D. A. Miller, estos personajes, que funcionan como un "amateur supplement" de la policía, logran entrar discretamente en el espacio doméstico sin alterar la paz burguesa, dado que no llevan uniforme y eso les permite generar confianza (2011: 8). De todos modos, la posición de estos hombres en la construcción del orden burgués patriarcal es por lo menos ambigua. 
Dentro del policial, el lazo afectivo e intelectual entre los hombres conspira contra la vida familiar y doméstica. Holmes y Watson, Dupin y el narrador anónimo de sus hazañas desarrollan una vida doméstica aislada, que prescinde por completo del contacto con las mujeres, además de que una de las características fundamentales de la configuración de los detectives es el rechazo absoluto del vínculo amoroso (con la mujer). Este elemento puede ser visto como otra modulación de las uniones o conjuros masculinos de científicos del siglo XIX, que también conspiran contra la familia y suponen una fuerte dosis de misoginia. En El hombre de arena, en Frankenstein o el moderno Prometeo, el exceso de ciencia termina por destruir la posibilidad de la unión amorosa heterosexual (tal como, en El halcón maltés, Sam Spade destruye la unión amorosa de Iva y Miles Archer).

La misoginia de los hombres es un rasgo presente desde los comienzos del género, que se exacerba por el crimen prototípico, el asesinato de mujeres, convertido en misterio intelectual y deleite espiritual de los caballeros. Asimismo, todo en el género parece apuntar a la crítica de la familia y la vida doméstica, y consecuentemente a aquello que es su emblema tradicional, la mujer.

Estos elementos son comunes a las dos vertientes más vigorosas del género policial en la literatura, la policial clásica y la serie negra. Ambas presentan un aspecto compartido en cuanto a los vínculos de sus personajes básicos, y los de éstos con el resto de la sociedad: el policial se basa en la amistad entre dos hombres diferentes, de desigual capacidad; en el policial de enigma, se trata por lo general de hombres de inteligencia desigual -Dupin y el narrador anónimo de sus aventuras, en los cuentos de Poe-, Sherlock Holmes y Watson -en las narraciones de Conan Doyle-, Nero Wolf y Archie Goodwin -en los policiales de Rex Stout-. En el policial negro, en cambio, estos dos hombres tienen destreza física y dinámica y capacidades prácticas desiguales: habilidad para luchar o disparar, conocimiento del mundo del hampa, contactos con la policía o los soplones. En The False Burton Combs-considerado el primer relato de la serie negra- esta amistad entre individuos desiguales se da de manera embrionaria pero duplicada, entre el falso Burton Combs y el verdadero, y entre el héroe y John B. Combs. En El halcón maltés, la vemos entre los socios detectives, Sam Spade y Miles Archer: Archer es tan poco diestro que muere en las primeras páginas de la novela engañado de la manera más tonta. Spade ha engañado a Archer con su mujer, Iva, pero luego de la muerte de Archer, Spade guarda completa fidelidad a su socio en el ámbito de la investigación, y también, ahora, en el ámbito del amor. En The Big Sleep, esta amistad se da entre Marlow y el general Sternwood, que dialogan y sudan y toman "juntos" coñac en un invernadero poblado de orquídeas, con un clima agobiante: Marlow toma y Sternood disfruta viendo cómo él toma. En Farewell, My Lovely, la dupla se da entre Marlow y Moose Malloy, una especie de gorila que le encarga compulsivamente a Marlow la búsqueda de su exnovia. En todos estos casos, tenemos una pareja de hombres con un interés común, la investigación, la búsqueda de una persona, la solución de un problema, etc. Estos hombres dejan de lado sus diferencias y cooperan para alcanzar su objetivo o realizar una tarea de la que alguien debe hacerse cargo. Se trata de get de job done: de esto se trata ser hombre, para los detectives, pero no sólo para ellos.

La vida de muchos detectives del género y su casa son en sí una recusación de la vida familiar. Nada hay allí que convoque a la vida conjunta hogareña, pues el vínculo entre los hombres se desarrolla en el espacio de trabajo, que debe convertirse en la totalidad de la existencia. Es común que los hombres se queden a dormir e incluso a vivir en la oficina, o que transformen la casa en el espacio de trabajo. En esto, el policial coincide en sus inicios también con el género fantástico. En El hombre de arena el espacio del laboratorio, situado dentro del hogar familiar, hace explotar la casa. El abogado Coppelius, el hombre de arena, llega por las noches a la casa de Nathanael y 
arrastra al padre de familia a la ciencia que termina por destruir la casa y la familia. Por eso, no debe sorprender que los hombres, ya sea en la soledad, o en la unión, abocados a la ciencia, la magia o alguna cosa en el medio de ambas terminen por dar a luz formas de vida artificial (la criatura de Frankenstein..., Olimpia, en El hombre de arena, Alraune, en la novela homónima de Ewers, etc.).

Un último elemento ligado a esta amistad entre dos hombres de diferentes capacidades es el eros pedagógico. Esto se suele dar en la literatura policial con más frecuencia y de manera más plena que en las ficciones científicas, en que las relaciones entre maestro y discípulo son, antes bien, de amor-odio. Aquel con mayor capacidad, en algo o en todo, instruye al compañero, y esto fortalece la unión, cuando no la constituye enteramente. En el policial de enigma este elemento está vinculado con la deducción y con la vista, la capacidad para percibir rastros allí donde la mayor parte de los hombres no pueden hacerlo. De allí la lupa y la gorra de cazador que caracterizan a Sherlock Holmes. En los detectives intelectuales, en cambio, es como si la totalidad de un hombre estuviera compuesta por dos mitades, el detective intelectual, y su ayudante, que se encarga de desempeñar en el mundo empírico aquello que el armchair detective, el detective de sillón, ha ideado. Esto se puede ver con claridad en el sedentario Nero Wolf y su compañero, el muy activo Archie Goodwin.

En el cine, en cambio, una figura recurrente de aquel subgénero denominado police procedural es el investigador abocado casi por completo a su trabajo, que por lo tanto debe postergar a su familia y, ante todo, sus obligaciones matrimoniales. Esto se puede ver en clásicos de Hollywood (Pánico en las calles o La ciudad desnuda), pero también en algunas adaptaciones latinoamericanas de ese subgénero (por ejemplo, en Captura recomendada, de Don Napy). En muchos de estos films, la "familia policial" no solamente está por delante de la familia sin más; también en parte la reemplaza.

En el cine negro o film noir, en cambio, muchos estudios ya se han detenido en las configuraciones de las mujeres, fatales o no, así como en la ambigüedad de muchas de las representaciones masculinas. El "hombre en crisis", el "hombre débil", el "hombre dañado" o el "hombre duro" son algunas de las configuraciones más asiduas de las formas de la masculinidad en el cine negro. Esto no llama la atención si se piensa que se trata de un género cinematográfico -cabe aclarar que, para muchos, es un estilo o una modalidad; no necesariamente un género- que surgió durante la Segunda Guerra y se consolidó después de esta guerra. Surge, entonces, en un mundo en que los hombres han dejado el hogar para ir a luchar a otro continente y han regresado, en muchos casos, quebrados. La bibliografía, sin embargo, ya ha señalado tiempo atrás la gran heterogeneidad de las representaciones en términos de género, preferencias e identidades sexuales (Dyer, 1998; Kaplan 1998), que en un comienzo habían sido percibidas como muy esquemáticas, unívocas y misóginas.

Los estudios que cruzan el noir con la perspectiva de género se han enfocado en general en el cine de Hollywood y sólo de manera reciente y en gran medida marginal han abordado otras cinematografías. Recién a comienzos del nuevo milenio, se ha incrementado este tipo de estudios. De manera similar, si bien los vínculos entre la literatura y el cine ya llevan mucho tiempo de ser estudiados, los estudios transmediales -que incluyan los diferentes pasajes e interacciones del cine, con la televisión, el comic, la radio, las series- son de desarrollo reciente. Este dossier pretende, modestamente, contribuir a comenzar a saldar estas deudas.

Dentro del ámbito de Latinoamérica, las tradiciones de las ficciones policiales, criminales y negras presentan muchos puntos de contacto con su desarrollo en los ámbitos europeo y estadounidense. En los comienzos de la literatura policial latinoamericana, por ejemplo, no faltan en absoluto los hombres de ciencia, los conjuros masculinos, 
el homoerotismo o la misoginia. Uno de los escritores más importantes de los inicios del policial en Latinoamérica, Eduardo Ladislao Holmberg, ha sido también uno de los principales autores de ficción científica del siglo XIX y comienzos del XX. Como en E.T.A. Hoffmann, como en Poe, coinciden en su literatura los autómatas y los detectives. Pero a diferencia de la temprana detective de Hoffmann -la señorita de Scuderi-, sus detectives están inspirados en el modelo científico de la medicina. De hecho, en los comienzos de la literatura policial latinoamericana proliferan las escenas de autopsias, vivisección y visitas a la morgue -esto se puede ver en las novelas de Luis V. Varela, varios relatos de Holmberg ("Más allá de la autopsia", "La bolsa de huesos"), en "El despojo sangriento", de Alberto Edwards Vives, entre otras-, en concordancia con la predominancia de la cultura científica y el predominio del modelo médico sobre el que fue creado Sherlock Holmes. De hecho, no son infrecuentes los médicos y estudiantes de medicina como personajes de estas narraciones (criminales, sospechosos, detectives). Casi toda La bolsa de huesos se desarrolla en la Facultad de Medicina de la Universidad de Buenos Aires o en casas de diferentes médicos, hombres de ciencia o estudiantes de medicina. Esto se vincula en la narración con el misterio de la mujer, pero en este caso con el misterio de la mujer que, travestida, se ha convertido en asesina. Clara -el mismo nombre que lleva la novia de Nathanel en El hombre de arena-, travestida como Antonio Lapas, se va a vivir con sus presuntos compañeros de estudios tras poco tiempo de conocimiento, de manera similar a lo que veíamos que sucedía cual Holmes y Watson o Dupin y el narrador anónimo de sus relatos. También aquí la fascinación y la vocación por el conocimiento son componentes fundamentales, pero Holmberg introduce numerosas e interesantes variaciones. Luego de que el vínculo se desarrolla y se afirma, Clara los enamora y se revela como mujer, para luego matarlos extrayéndoles una costilla. La conversión de Clara en asesina serial tiene por causa un amor despechado, y el narrador, escritor, médico y científico, reinstaura el orden social descubriendo el misterio -con el auxilio de otros médicos y científicos- e induciéndola al suicidio. Por lo general, las cuestiones de la identidad genérica, la virginidad de la mujer, la infidelidad o las disidencias sexuales ocupan un lugar importante en esta tradición, tal como se puede ver en La huella del crimen, 1877, Clemencia, 1877, en Argentina; Póstumo, el transmigrado, 1872, en Puerto Rico; "Un hombre muerto a puntapiés", 1926, en Ecuador; etcétera.

En este último relato, en que se conjetura el asesinato salvaje a golpes de un homosexual por parte de un padre de familia, la explicación del detective no pasa de ser una serie ostensible de conjeturas absurdas casi sin apoyo en elemento de la realidad alguno. De este modo, se deja en evidencia un modo de pensamiento que nada tiene que ver con los razonamientos deductivos y las explicaciones científicas, sino, antes bien, con los prejuicios y los modos de constitución de mandatos de masculinidad y de exclusión social. Por otro lado, el femicidio de El asesino sentimental (1925) es narrado desde el punto de vista de quien lo cometió. Esto, por un lado, elimina la condena del crimen; por otro, pone en duda su concreción a partir de una fundamentación filosófica que escinde el orden material y el espiritual. ${ }^{2}$ En "El tres de espadas", uno de los dos relatos que han quedado del primer detective mexicano, Pancho Reyes, una cofradía de hombres de las fuerzas armadas, unidos por un pacto de silencio, lleva a cabo una serie de asesinatos, incluyendo el de una mujer, la señora Nuñez -quizá la primera detective femenina en la literatura latinoamericana-, quien los había descubierto.

En algunos de los relatos y novelas policiales más destacados de la literatura latinoamericana -"Emma Zunz", "La muerte y la brújula", "En defensa propia", "La loca y el relato del crimen", La virgen de los sicarios, Plata quemada, La pesquisa, las sagas de los

2 Muy comparable es el caso de "La pierna de plomo" (Nicolás Olivari), relato en que también el narrador es el femicida y la narración se basa en el crimen y la “explicación” de las causas. 
detectives Héctor Belascoarán Shayne de Paco Ignacio Taibo II y Mario Conde de Leonardo Padura, sólo por nombrar algunos entre los más relevantes-, los mandatos de masculinidad y las disputas por los diferentes modelos de masculinidad siguen estando en el centro. Desde los detectives puramente intelectuales, pasando por los asesinos que manejan el cuchillo, los rufianes que conocen el manejo del revolver pero no del cuchillo o los sicarios homosexuales, hasta los actuales criminales y detectives inscriptos en la cultura gay y/o queer, se despliega toda la entera gama que va desde el homoerotismo del siglo XIX hasta la cultura actual de la diversidad en el siglo XXI.

También en el audiovisual latinoamericano pueden verse las diferentes instanciaciones de los cruces entre lo policial / criminal y los mandatos -y sus rupturas- de género. Ejemplo de esto son, entre muchas otras, Apenas un delincuente, Alias Gardelito o las más recientes Tumberos, Un gallo para Esculapio, El secreto de sus ojos, El ángel, El club, La virgen de los sicarios, O Invasor, Matar a un hombre, Perro come perro, Heli, Carmín tropical, Luna de cigarras y Pájaros de verano. De la indagación de estas cuestiones se ocupan los trabajos del dossier.

En la serie de artículos que presentamos aparece como objeto de análisis un conjunto de temas vinculados a la representación de la masculinidad: paternidad, virilidad, la capacidad de matar, la jerarquía, entre otros. Si las figuras masculinas asociadas a los géneros que representan el crimen han cristalizado en el imaginario del público en estereotipos patriarcales como el detective recio, el gángster desbordado e incontrolable o el asesino desalmado que abusa de la violencia, estos trabajos encuentran importantes fisuras en esos esquemas establecidos. Leer las obras a través de las teorías sobre el género permite mostrar una serie de contradicciones en esos modelos, incluso en la ficción latinoamericana, atravesada por otro estereotipo como el del "macho latino". Los protagonistas -en sus roles, sus acciones, sus relaciones con otras expresiones de género, su lugar en la sociedad, su uso de los espacios- aparecen siempre en situaciones plagadas de contradicciones entre lo que deben ser y lo que realmente son. Estas contradicciones no sólo surgen en representaciones patriarcales sino también en aquellas que suponen rupturas con los modelos hegemónicos y se muestran críticas con ese sistema.

Los artículos no sólo ayudan, entonces, a entender el problema en diferentes contextos (Argentina, Brasil, Perú, México) y en diferentes momentos históricos de los siglos XX y XXI, sino también a reflexionar sobre el funcionamiento del género policial y sus particularidades en los procesos de adaptación y transformación a distintos parámetros y modelos de masculinidad. El sistema global del género policial/criminal que cuenta, entre otros subgéneros, con el noir, el police procedural, el semidocumental, el neopolicial, el neo-noir, el drama carcelario, etcétera, además de las transposiciones y adaptaciones a los diferentes formatos y lenguas, permite mostrar y analizar las características de las masculinidades locales. Una constante que aparece en los análisis de este dossier es la relación de esos sujetos masculinos con el Estado (y otras instituciones y organizaciones como la Iglesia y las empresas, por ejemplo). Esas masculinidades se organizan así en diferentes roles promovidos por la sociedad: jefes de familia, padres, agentes de la ley, etcétera. De modo que los desvíos de esos roles abren la puerta al mundo del crimen, pues se trata de una transgresión al orden estatal, social, familiar. El homoerotismo, el abandono de la función paterna, la conformación de modelos de familia alternativa ponen a los sujetos masculinos en relación con el delito y al mismo tiempo señalan de modo indirecto el carácter opresivo estatal en la definición de los roles de género.

Así, el orden simbolizado se encarga a menudo de restringir y reglamentar las libertades sexuales, vinculadas con los mandatos de masculinidad y la institución matrimonial. 


\section{Q Bibliografía}

»Bernini, E. (2021). “El noir peronista. Christensen y la trilogía William Irish”. En: Setton. R. y Pignatiello, G. (eds.), El género policial argentino en el período clásico (1930-1960) entre Sur y el peronismo. Modelos narrativos, tensiones y debates culturales. Harlingen (Texas): Libros Medio Siglo, 213-219.

»Connell, R. (1995). “La organización social de la masculinidad”. En: Valdés, T. y Olavarría, J. (ed.), Masculinidad/es: poder y crisis. Santiago de Chile: Ediciones de las Mujeres. En: "http://www.pasa.cl/wp-content/uploads/2011/o8/La_ Organizacion_Social_de_la_Masculinidad_Connel_Robert.pdf”; obtenido el 17/8/2021, 1-25.

»Dyer, R. (1998). “Resistance Through Charisma: Rita Hayworth and Gilda”. En: Kaplan, E. A. (ed.), Women in Film Noir. London: BFI, 115-122.

»Federici, S. (2010). Calibán y la bruja. Traducción: Hendel, V. y Touza, L. S. Madrid: Traficante de sueños.

" Gilbert, S.M. y Gubar, S. (1984). The Madwoman in the Attic. New Haven-London: Yale University Press.

"Kaplan, E. A. (1998). “The Place of Women in Fritz Lang's The Blue Gardenia”. En Kaplan E. A. (ed.), Women in Film Noir. London: BFI, 81-88.

»Miller, D. A. (2011). The Novel and the Police. Berkeley/London: University of California Press.

»Poe, E. A. (1979). Forty-Two Tales. London: Octopus.

"Segato, R. (2016). La guerra contra las mujeres. Madrid: Traficante de sueños. 